\title{
Intracardiac left atrial tuberculoma in an eleven- month-old infant: case report
}

\author{
Cantinotti $\mathrm{M}^{1 \dagger}$, De Gaudio $\mathrm{M}^{2 \dagger}$, de Martino $\mathrm{M}^{2}$, Assanta $\mathrm{N}^{1}$, Moschetti $\mathrm{R}^{1}$, Veneruso $\mathrm{G}^{2}$, Crocetti $\mathrm{M}^{1}$, Murzi $\mathrm{B}^{1}$, \\ Chiappini $\mathrm{E}^{2}$ and Galli $\mathrm{L}^{2^{*}}$
}

\begin{abstract}
Background: Cardiac tuberculosis is rare and usually manifests as tuberculous pericarditis. Involvement of other part of the heart is unusual and descriptions in the pediatric literature are confined to few case reports regarding mainly myocardial tuberculosis.
\end{abstract}

Case presentation: We describe a case of pulmonary miliary tuberculosis associated with intracardiac left atrial tuberculoma in an immunocompetent eleven-month-old infant successfully treated with surgery and antituberculous therapy.

Conclusion: Although unusual, involvement of endocardium in disseminated tuberculosis should be kept in mind.

\section{Background}

Tuberculosis (TB) is one of the top ten causes of death among children worldwide and it is a direct consequence of adult TB [1]. In the natural history of childhood pulmonary TB, primary infection before two years of age frequently progresses to disease within twelve months [2]. Young age and human immunodeficiency virus type 1 (HIV-1) infection are the most important risk factors for severe or disseminated disease $[2,3]$. The involvement of the heart in TB is a very rare clinical condition both in adults and children $[4,5]$. We report here a case of pulmonary miliary TB associated with intracardiac left atrial tuberculoma in an eleven-monthold infant successfully treated with surgery and antituberculous therapy.

\section{Case presentation}

An eleven-month-old female infant was referred to her local hospital for a 2-week history of intermittent fever, cough, dyspnea, night sweats and poor feeding. She was initially treated with amoxicillin-clavulanic acid for presumed upper respiratory tract infection without improvement.

\footnotetext{
* Correspondence: luisa.galli@unifi.it

† Contributed equally

${ }^{2}$ Department of Sciences for Woman and Child's Health, University of

Florence, Anna Meyer Children's University Hospital, Florence, Italy

Full list of author information is available at the end of the article
}

On examination, she was underweight for age, had a temperature of $37.5^{\circ} \mathrm{C}$, pulse was regular with a rate of 130 beats per minute, blood pressure was normal, transcutaneous oxygen saturation was $96 \%$ on room air, and respiration rate was 40 breaths per minute. A few crackles were heard bilaterally and a mild systolic murmur was noted. She had soft, mobile, non tender, small volume cervical lymph nodes with normal overlying skin and no evidence of discharge. The rest of the clinical examination was unremarkable. A complete blood count at presentation revealed a hemoglobin of $10.4 \mathrm{mg} / \mathrm{dL}$, white cell count of $18 \times 10^{3} \mathrm{cell} / \mu \mathrm{L}$ with neutrophilia, and a platelet count of $660 \times 10^{3} \mathrm{cell} / \mu \mathrm{L}$. Both biochemistry profile and $C$ reactive protein levels were normal. HIV-1 serology was nonreactive. Chest X-Ray (CXR) revealed diffuse, bilateral, small lung nodules which could suggest acute pulmonary miliary TB (Figure 1). The tuberculin skin test (TST) and the QuantiFERONTB Gold test were negative. Results of acid-fast bacilli (AFB) smears on three early morning gastric aspirates were negative. Polymerase chain reaction (PCR) for Mycobacterium tuberculosis complex and colture on gastric aspirates were pending. Family members were investigated for TB, but both parents had negative CXR and TST and the source of infection was not identified.

On day 3 after admission due to the presence of a mild systolic murmur and the persistence of intermittent dyspnea, echocardiography $(\mathrm{ECHO})$ was performed
C Biomed Central

(c) 2011 Cantinotti et al; licensee BioMed Central Ltd. This is an Open Access article distributed under the terms of the Creative Commons Attribution License (http://creativecommons.org/licenses/by/2.0), which permits unrestricted use, distribution, and reproduction in any medium, provided the original work is properly cited. 


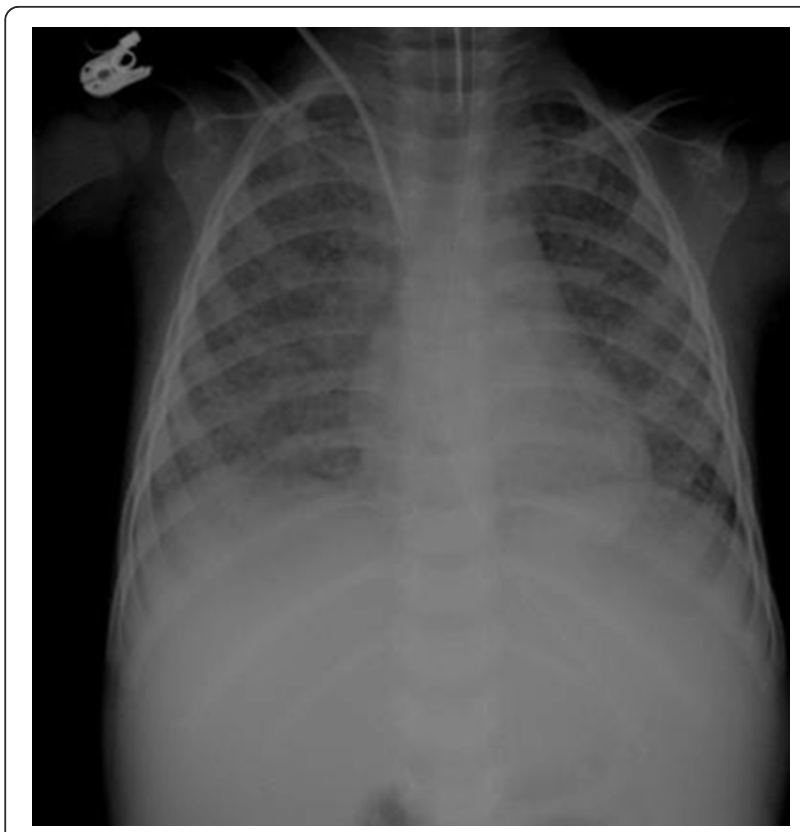

Figure 1 Chest X-Ray. Diffuse, bilateral, small lung nodules suggestive of acute miliary pulmonary tuberculosis.

and revealed a voluminous left atrial intracavitary pedunculated mass prolapsing during the diastole from the right lower pulmonary vein into the left ventricle through the mitral valve (Figure 2). No mitral stenosis and only trivial mitral regurgitation were noted. The patient was immediately transferred to the cardio-surgical unit and complete excision of an homogeneous and yellowish in color mass was performed through median sternotomy, under cardiopulmonary bypass. Histopathological examination of the removed mass revealed fibrotic tissue with mixed inflammatory cells and necrotic debris with a vaguely granulomatous appearance and AFBs were found. PCR for Mycobacterium tuberculosis complex was positive on the removed mass and on previous gastric aspirates.

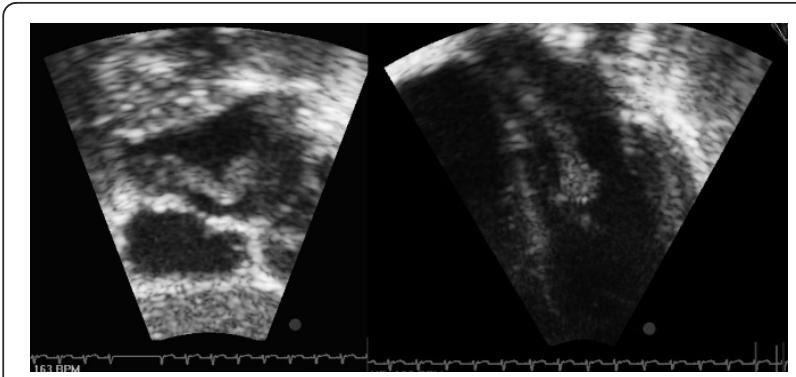

Figure 2 Trans-thoracic echocardiographic subcostal and parasternal views. A voluminous left atrial intracavitary pedunculated mass prolapsing during the diastole from the right lower pulmonary vein into the left ventricle through the mitral valve.
Three days after surgery, a chest computed tomography $(\mathrm{CT})$ scan revealed widespread miliary nodules, compatible with acute pulmonary miliary $\mathrm{TB}$ and showed a right upper lobe consolidation (Figure 3). The cranial contrast-enhanced CT scan and the abdominal ultrasound were normal.

Antituberculous therapy with streptomycin $(20 \mathrm{mg} / \mathrm{kg}$ intramuscularly once daily), isoniazid (10 $\mathrm{mg} / \mathrm{kg}$ orally once daily), rifampicin (15 $\mathrm{mg} / \mathrm{kg}$ orally once daily), ethambutol $(20 \mathrm{mg} / \mathrm{kg}$ orally once daily), pyrazinamide (30 mg/kg orally once daily) and corticosteroids were started immediately with remarkable improvement in her symptoms in two weeks. Streptomycin was suspended once the drug susceptibility results showed no resistance to the first-line antituberculous drugs. Coltures of gastric aspirates and tissue specimens of the removed mass confirmed Mycobacterium tuberculosis. Further investigations on possible source case found a Romanian grandmother with active pulmonary TB.

Echocardiograms were performed at regular postoperative intervals and no residual lesions were noted. The infant completed 1 year of antituberculous therapy, recovered completely, and did well during the whole follow-up.

\section{Discussion}

To our knowledge, this is the youngest patient reported with a cardiac tuberculoma and the first infant with an endocardial tuberculoma in a left heart chamber successfully treated.

Cardiac TB is a rare disease and it most usually manifests as tuberculous pericarditis [3]. Involvement of other parts of the heart is unusual and descriptions in

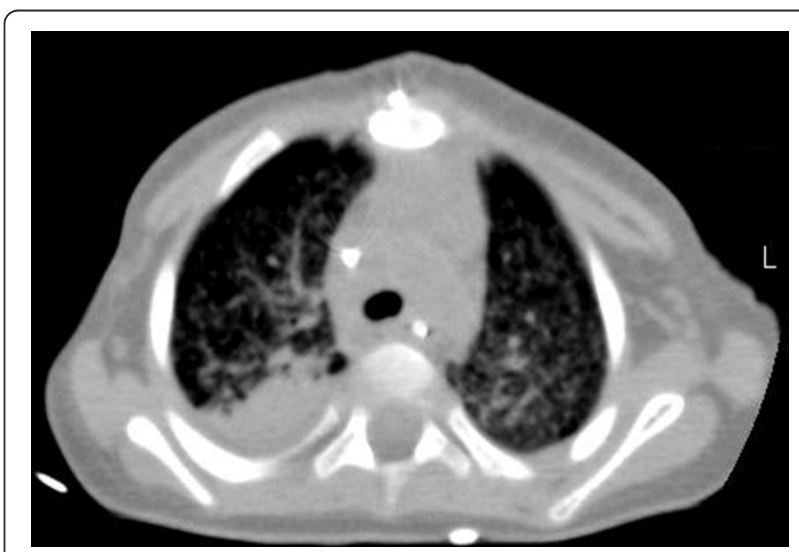

Figure 3 Chest Computed Tomography. Innumerable tiny, welldefined, miliary nodules throughout the lungs, and bronchovascular structures, a consolidation with air bronchogram in the posterior segment of the right upper lobe and an initial consolidation in the lateral segment of the right inferior lobe with evident local bronchiectasis. 
the pediatric literature are confined to few case reports regarding mainly myocardial TB [5-8]. Myocardial TB may occur secondary to haematogenous spread from a remote tuberculous focus, lymphatic spread from mediastinal lymph nodes, or direct involvement from the adjacent pericardium [5]. Three distinct forms of myocardial TB have been recognized: miliary, diffuse infiltrating, or nodular with central caseation or tuberculoma [5,9]. Tuberculoma, a mass-like manifestation of the disease, was first reported by Morgagni in $1761[7,9,10]$. Myocardial tuberculomas are mostly located in the right heart and particularly in the wall of the right atrium [4]. They are usually sharply demarcated from the surrounding parenchyma and may be single or multiple $[4,9]$.

The infant we described had a miliary pattern pulmonary TB. The infection may have spread hematogenously to the left heart chambers causing a single voluminous left atrial endocardial tuberculoma. Tuberculoma of the heart has been associated to congenital heart diseases in children, but our patient had no anatomic abnormalities [6]. In addition, disseminated TB is often associated with acquired immunodeficiency syndrome, but our patient was immunocompetent and negative for HIV-1 [1].

Clinically, cardiac tuberculomas may be asymptomatic, or presenting with pulmonary vein obstruction due to left atrial mass lesions, left ventricular aneurysm, right ventricular outflow tract obstruction, superior vena cava obstruction, coronary artery occlusion, impairment of ventricular contractility, ventricular rupture, aortic insufficiency or regurgitation, cardiac arrhythmia, complete heart block, and sudden cardiac death $[8,9,11,12]$. Our patient presented only a systolic murmur and intermittent dyspnea.

The treatment of cardiac TB is, first of all, antituberculous therapy [7]. Complete recovery of patient's signs and symptoms along with imaging evidence of cardiac involvement resolution on antituberculous therapy has been reported previously [8]. However, if the diagnosis remains questionable or in cases of severe hemodynamic compromise, refractory arrhythmias or threatening thromboembolism, the surgical resection of tuberculoma may be considered $[9,13]$. In 1997, Shoeman JF et al. described an infant with miliary TB and an acute stroke caused by an infected thromboembolus which arose from a suspected endocardial tuberculous vegetation [14]. In our patient the voluminous tuberculoma prolapsing during the diastole had a high risk of systemic embolization and a surgical resection was immediately performed. Subsequently, a 12-month course of antituberculous therapy to prevent hematogenous dissemination and to treat pulmonary parenchymal disease was completed with total recovery.
The infant we described had a CXR suggestive of acute miliary pulmonary TB which was supported by the chest CT performed few days later. However TST, QuantiFERON-TB Gold test, and microscopic examination of gastric aspirates were negative. Only PCR and coltures of gastric aspirates and tissue specimens of the removed mass revealed Mycobacterium tuberculosis. This confirms that up to $40 \%$ of immunocompetent young children with colture-documented active TB do not react to the TST, nor have a positive QuantiFERON-TB Gold test, and have a less than $15 \%$ probability of having an AFB smear positive gastric aspirate [1,15-17].

\section{Conclusions}

The peculiarity of TB in the pediatric population is the imperceptible and often rapid progression from infection with Mycobacterium tuberculosis to active disease [1]. As a matter of fact, the risk of progression depends on various factors, including age at exposure, nutritional and immune status, genetic factors, virulence of the organism, and magnitude of initial infection [1]. Pulmonary parenchymal disease and intrathoracic adenopathy are the most common clinical manifestations of pediatric TB, accounting up to $80 \%$ of all cases $[2,16]$. Among extrapulmonary manifestations, cardiac TB is extremely rare. However, negative QuantiFERON-TB Gold test, TST, and microscopic examination on gastric aspirates should not dissuade pediatricians from further investigations in infants for active TB. Although rare, disseminated TB with heart involvement should be suspected in immunocompetent infants with an intracardiac mass.

\section{Consent}

Written informed consent was obtained from the parents for publication of this case report and any accompanying images. A copy of the written consent is available for review by the Editor-in-Chief of this Journal.

\section{Author details \\ ${ }^{1}$ G. Monasterio Tuscan Foundation, Heart Hospital, National Research Institute, Massa, Italy. ${ }^{2}$ Department of Sciences for Woman and Child's Health, University of Florence, Anna Meyer Children's University Hospital, Florence, Italy.}

\section{Authors' contributions}

CM and DGM drafted the manuscript together and should be both considered first author. $\mathrm{dMM}, \mathrm{EC}$ and VG participated in the design of the paper and revised it critically for the infectious diseases content. BM, AN, MR and $M C$ participated in the design of the paper and revised it critically for the cardio-surgical content. LG help to draft the manuscript and revised the final version of the manuscript. All authors read and approved the final manuscript.

\section{Competing interests}

The authors declare that they have no competing interests. 


\section{References}

1. Swaminathan S, Rekha B: Pediatric tuberculosis: global overview and challenges. Clin Infect Dis 2010, 50:184-194.

2. Marais BJ, Gie RP, Schaaf HS, Hesseling AC, Obihara CC, Starke JJ, et al: The natural history of childhood intra-thoracic tuberculosis: a critical review of literature from the prechemotherapy era. Int J Tuberc Lung Dis 2004, 8:392-402.

3. Nelson LJ, Wells CD: Global epidemiology of childhood tuberculosis. Int J Tuberc Lung Dis 2004, 8:636-647.

4. Licht J, Diefenbach C, Stang A, et al: Tuberculoma of the myocardium: a rare case of intra-vitam diagnosis. Clin Res Cardiol 2009, 98:331-333.

5. Jagia P, Gulati GS, Sharma S, Goyal NK, Gaikwad S, Saxena A: MRI features of tuberculoma of the right atrial myocardium. Pediatr Radiol 2004, 34:904-907.

6. Santos CL, Moraes F, Moraes CR: Obstruction of the right ventricular outflow tract caused by a tuberculoma in a patient with ventricular septal defect and aneurysm of the membranous septum. Cardiol Young 1999, 9:509-511.

7. Gulati GS, Singh S, Arepalli D, Sharma S, Kothari SS, Airan B, et al: Superior vena caval obstruction after complete resolution of cardiac tuberculoma. Clin Radiol 2008, 63:605-609.

8. Chang BG, Ha JW, Chung N: Intracardiac tuberculoma. Ann Thorac Surg 1999, 67:226-228.

9. Maeder M, Ammann P, Rickli $H$, et al: Fever and night sweats in a 22-yearold man with mediastinal mass involving the heart. Chest 2003, 124:2006-2009.

10. Vaideeswar P, Pandit SP, Deshpande JR: Tuberculoma of the heart. Cardiovasc Pathol 2006, 15:55-56.

11. O'Neill PG, Rokey R, Greenberg S, et al: Resolution of ventricular tachycardia and endocardial tuberculoma following antituberculosis therapy. Chest 1991, 100:1467-1469.

12. Al Nasser I, Anwar AM, Nosir YF, et al: Bicaval obstruction complicating right atrial tuberculoma: the diagnostic value of cardiovascular MR. J Cardiovasc Magn Reson 2008, 20:10-60.

13. Rodriguez $E$, Soler R, Juffè $A$, et al: CT and MR findings in a calcified myocardial tuberculoma of the left ventricle. $J$ Comput Assist Tomogr 2001, 25:577-579.

14. Schoeman JF, Rutherfoord GS, Hewlett RH: Acute stroke in a child with miliary tuberculosis. Clin Neuropathol 1997, 16:303-308.

15. American Academy of Pediatrics: Red Book: 2009 Report of the Committee on Infectious Disease. In Tuberculosi.. 28 edition. Edited by: Pickering LK, Baker CJ, Kimberlin DW, Long SS. Elk Grove Village, IL: American Academy of Pediatrics; 2009:680-698.

16. Kampmann B, Whittaker $E$, Williams A, et al: Interferon-gamma release assays do not identify more children with active tuberculosis than the tuberculin skin test. Eur Respi J 2009, 33:1374-1382.

17. Bianchi L, Galli L, Moriondo M, et al: Interferon-gamma release assay improves the diagnosis of tuberculosis in children. Pediatr Infect Dis $J$ 2009, 28:510-514.

\section{Pre-publication history}

The pre-publication history for this paper can be accessed here: http://www.biomedcentral.com/1471-2334/11/359/prepub

doi:10.1186/1471-2334-11-359

Cite this article as: $M$ et al: Intracardiac left atrial tuberculoma in an eleven-month-old infant: case report. BMC Infectious Diseases 2011 11:359.

\section{Submit your next manuscript to BioMed Central and take full advantage of:}

- Convenient online submission

- Thorough peer review

- No space constraints or color figure charges

- Immediate publication on acceptance

- Inclusion in PubMed, CAS, Scopus and Google Scholar

- Research which is freely available for redistribution

Submit your manuscript at www.biomedcentral.com/submit
Ciomed Central 